\title{
Influence of Al Concentration on the High Temperature Cyclic Oxidation Resistance Behavior of Fe-15Cu Alloys
}

\author{
Lingyun Bai, Xianchao Xu, Junhuai Xianga , Songping Wang, Ting Wang \\ Jiangxi Key Laboratory of Surface Engineering, Jiangxi Science and Technology Normal University, \\ Nanchang 330013, China \\ axiangjunhuai@163.com
}

Keywords: high temperature oxidation resistance; Fe-15Cu; Al concentration; the oxide film

\begin{abstract}
The cyclic oxidation behaviors of $\mathrm{Fe}-15 \mathrm{Cu}$ alloys with different $\mathrm{Al}$ concentration at $800{ }^{\circ} \mathrm{C}$ were studied. The oxidation kinetics showed that the oxidation process of Fe-15Cu alloys followed the parabolic law, Fe-15Cu-5Al alloy was oxidized more seriously than that of $\mathrm{Fe}-15 \mathrm{Cu}-15 \mathrm{Al}$ alloy. Analysis of the XRD results indicated that the oxides obtained on the lower $\mathrm{Al}$ concentration alloy was more complicated and the matrix metals were oxidized heavily, on the other side, the oxides obtained on the surface of Fe-15Cu-15Al alloy were simple, while the $\mathrm{Al}_{2} \mathrm{O}_{3}$ broke off from the surface, there were mainly pure matrix metals left as detected by the XRD and the SEM methods. The higher $\mathrm{Al}$ concentration gave the higher oxidation resistance of the alloy, but the adhesion of the protective $\mathrm{Al}_{2} \mathrm{O}_{3}$ should be improved in the next work.
\end{abstract}

\section{Introduction}

High temperature oxidation resistance alloys are such kind of materials with fine structure stability and corrosion resistance, which could be used up to or higher than $650{ }^{\circ} \mathrm{C}$. Usually these kind of materials comprises $\mathrm{Co}, \mathrm{Ni}$ and Fe based alloys, and also contained $\mathrm{Al}, \mathrm{Cr}$ or Si components, which would form the protective films, such us $\mathrm{Al}_{2} \mathrm{O}_{3}, \mathrm{Cr}_{2} \mathrm{O}_{3}$ or $\mathrm{SiO}_{2}$ [1-3]. Among theses matrix, $\mathrm{Fe}-\mathrm{Al}$ alloys exhibit outstanding oxidation, corrosion resistance because of the formation of protective $\mathrm{Al}_{2} \mathrm{O}_{3}$ scale on the materials' surface and also fine high temperature mechanical properties (Ref 7-9) so they were widely studied[4-6].

Al concentration will affect the oxidation resistance properties obviously, but the practical data still not be founded, so in this work, the $\mathrm{Fe}-15 \mathrm{Cu}$ alloys with different $\mathrm{Al}$ concentration were studied to research the oxidation properties of these alloys, in order to investigate the mechanism of the higher $\mathrm{Al}$ component in improving the oxidation resistance properties of the alloy.

\section{Experimental}

The alloys were prepared by melting 99.9\% $\mathrm{Fe}, 99.95 \% \mathrm{Cu}$ and $99.99 \% \mathrm{Al}$ in a vacuum arc furnace repeatedly. The ingots were annealed at $900{ }^{\circ} \mathrm{C}$ in vacuum annealing furnace $(\sim 1.3 \mathrm{~Pa})$ for $24 \mathrm{~h}$ and cut into $10 \times 10 \times 1.2 \mathrm{~mm}^{3}$ pieces by wire-electrode cutting, polished on SiC waterproof abrasive papers, then washed in distilled water, alcohol and acetone and dried immediately before use. The oxidation tests were carried out by oxidizing the specimen in atmosphere at $800{ }^{\circ} \mathrm{C}$ for 50 minutes, and then cooling in air for 10 minutes as one circle, the whole process included 24 circles. The mass change measurements of the specimens were carried out by electronic balance after cooling during each oxidizing circle. X-ray diffraction analysis (XRD), scanning electron microscopy (SEM) and energy-dispersive X-ray microanalysis (EDX) analysis were used to establish the crystal type, composition and spatial distribution of the oxidation products. 


\section{Results and Discussion}

3.1 Oxidation Kinetics
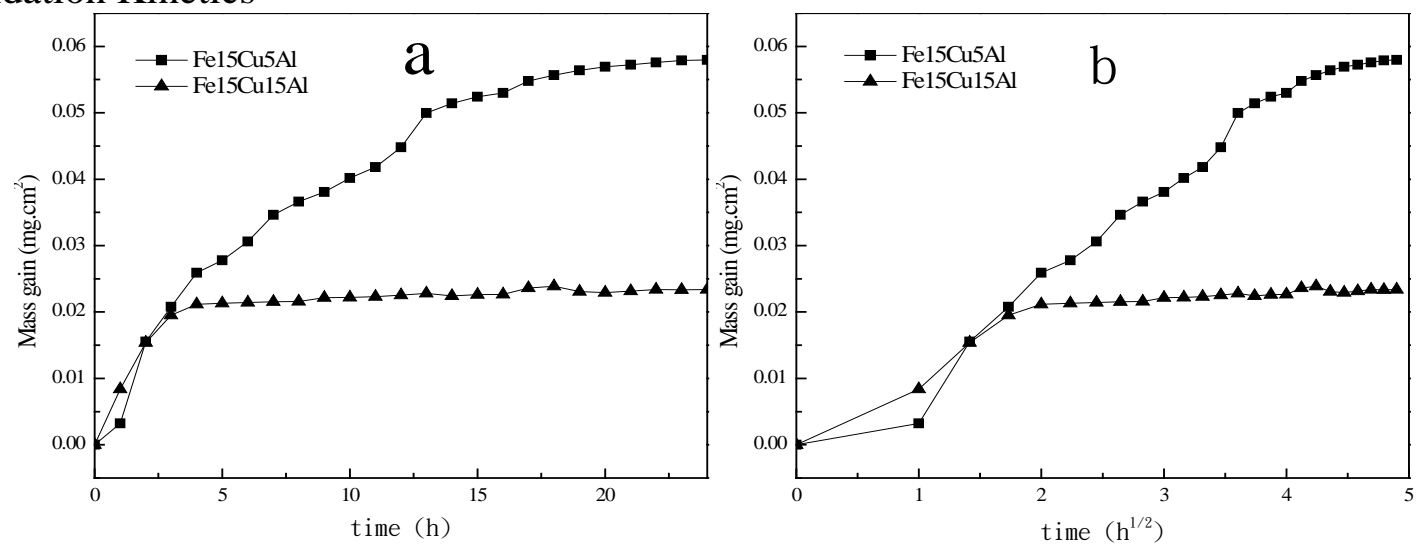

Fig.1 cyclic oxidation kinetics curves of Fe-15Cu alloys in atmosphere at 800

${ }^{\circ} \mathrm{C}$ for $24 \mathrm{~h}$ ( a, normal plots b, parabolic plots)

Fig. 1 a, b showed the cyclic oxidation kinetics curves and corresponding parabolic plots for the $\mathrm{Fe}-15 \mathrm{Cu}-5 \mathrm{Al}$ and $\mathrm{Fe}-15 \mathrm{Cu}-15 \mathrm{Al}$ alloys at $800{ }^{\circ} \mathrm{C}$ for $24 \mathrm{~h}$, respectively. It indicated that cyclic oxidation of the $\mathrm{Fe}-15 \mathrm{Cu}-5 \mathrm{Al}$ alloy approximately obeyed the parabolic rate law, and the parabolic rate constants were $2.89 \times 10^{-10} \mathrm{~g}^{2} \mathrm{~cm}^{-2} \mathrm{~s}^{-1}$ for the first stage (0 to $360 \mathrm{~min}$ ), $5.37 \times 10^{-11} \mathrm{~g}^{2} \mathrm{~cm}^{-2} \mathrm{~s}^{-1}$ for the second stage (360 to $960 \mathrm{~min}$ ), and $5.31 \times 10^{-11} \mathrm{~g}^{2} \mathrm{~cm}^{-2} \mathrm{~s}^{-1}$ for the last stage, respectively. The mass gain increased obviously at the initial stage and then gently. On the other side, the oxidation kinetics of Fe-15Cu-15Al alloy was composed of two stages, with the parabolic rate constant of $2.31 \times 10^{-11}$ (0 to $300 \mathrm{~min}$ ) and $2.07 \times 10^{-12} \quad \mathrm{~g}^{2} \mathrm{~cm}^{-2} \mathrm{~s}^{-1}$ (300-1440 $\mathrm{min}$ ), respectively.

3.2 XRD Analysis

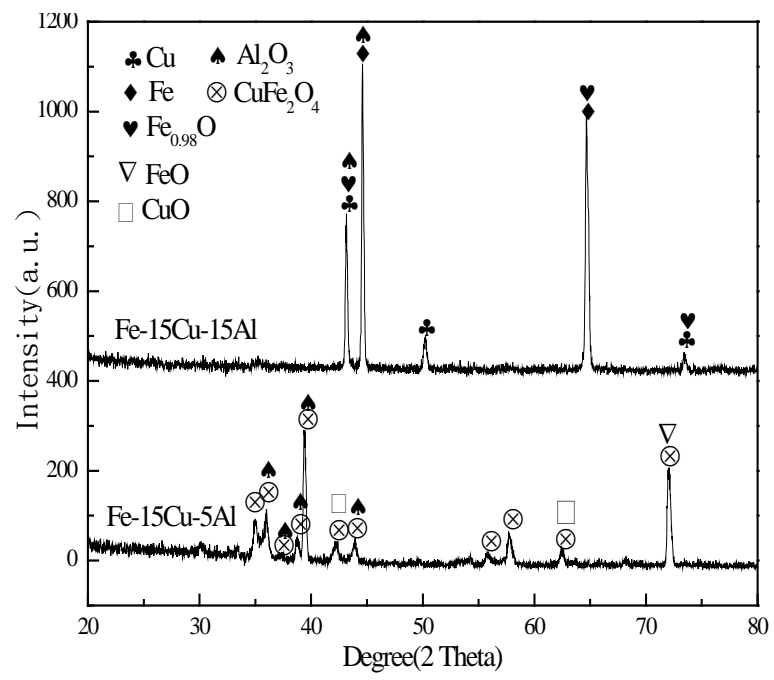

Fig.2 XRD curves of Fe-15Cu alloys in atmosphere at $800{ }^{\circ} \mathrm{C}$ for $24 \mathrm{~h}$

Fig.2 showed the XRD analysis of the $\mathrm{Fe}-15 \mathrm{Cu}$ alloys. The oxidation film formed on the Fe-15Cu-5Al alloy after $24 \mathrm{~h}$ oxidation at $800{ }^{\circ} \mathrm{C}$ was more complex, which was composed of $\mathrm{CuFe}_{2} \mathrm{O}_{4}$ (34-0425), $\mathrm{Al}_{2} \mathrm{O}_{3}$ (49-0134), $\mathrm{Cu}_{2} \mathrm{O}$ (34-1354) and $\mathrm{FeO}$ (06-0711). On the contrast, when the content of $\mathrm{Al}$ was heightened to 15 percent, that is for the $\mathrm{Fe}-15 \mathrm{Cu}-15 \mathrm{Al}$ alloy, the oxides on the surface were more simple. Because of bad adhesion between the protective oxide film $\mathrm{Al}_{2} \mathrm{O}_{3}$ and the matrix alloy, the main peaks were belong to the $\mathrm{Fe}$ (06-0696) and $\mathrm{Cu}$ (04-0836). From the analysis of the results, it could be see that, more $\mathrm{Al}_{2} \mathrm{O}_{3}$ film could be formed with higher $\mathrm{Al}$ content, and the other content of the matrix alloy were lightly oxide.

\subsection{Cross-sectional Microstructure and Composition}

Fig. 3 showed the cross-sectional morphology and concentration distribution of elements of oxide scales formed on Fe-15Cu-5Al alloy cyclic oxidized at $800{ }^{\circ} \mathrm{C}$ for $24 \mathrm{~h}$. The results showed that, 
serious and uneven oxidation was happened to the Fe-15Cu-5Al alloy. The outer region was mainly composed of oxides of $\mathrm{Fe}$ and $\mathrm{Al}$, and the inner region was oxides of $\mathrm{Al}$ and $\mathrm{Cu}$.
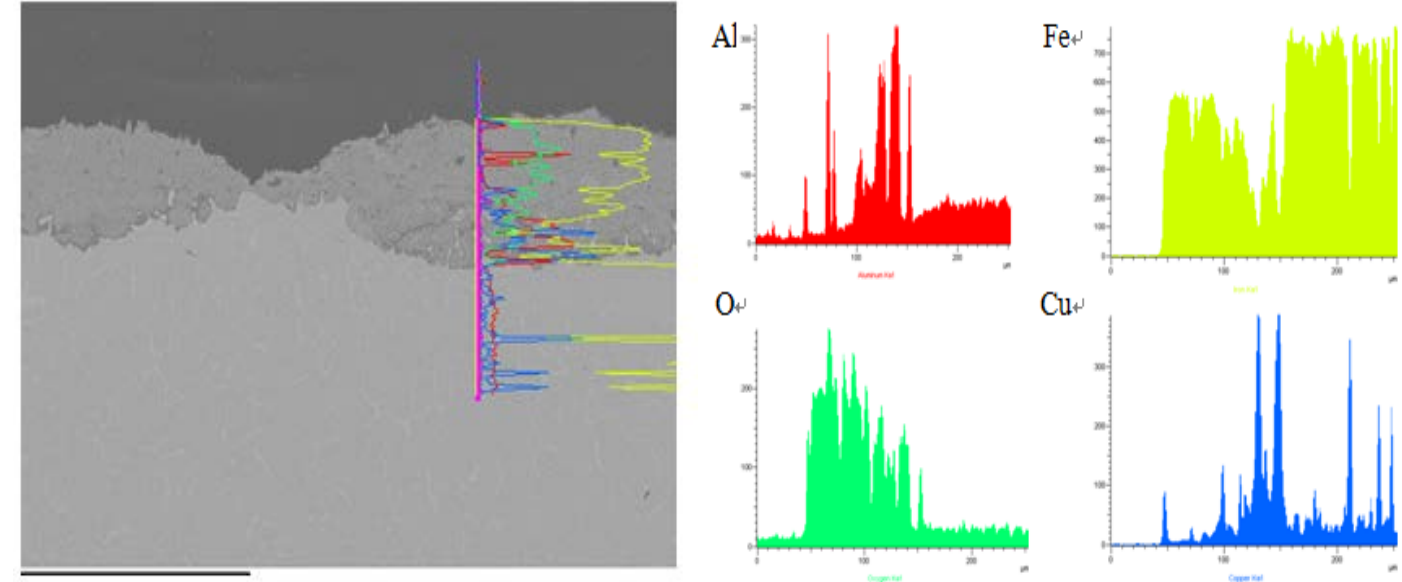

Fig.3 Cross-sectional morphology and concentration distribution of elements of oxide scales formed on $\mathrm{Fe}-15 \mathrm{Cu}-5 \mathrm{Al}$ alloy
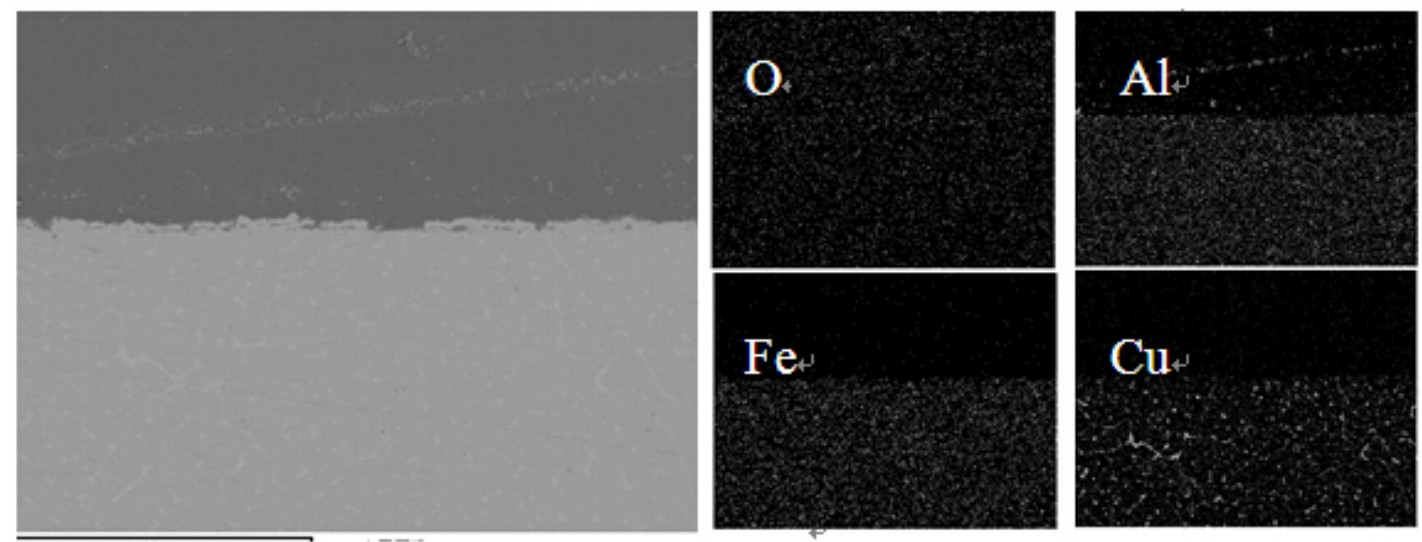

Fig.4 Cross-sectional morphology and concentration distribution of elements of oxide scales formed on Fe-15Cu-15Al alloy

Fig. 4 showed the cross-sectional morphology and elements distribution of oxide scales formed on Fe-15Cu-15Al alloy cyclic oxidized at $800{ }^{\circ} \mathrm{C}$ for $24 \mathrm{~h}$. The results showed that slightly oxidation was happened to the alloy, there was few oxides founded on the surface of the alloy and the outer $\mathrm{Al}_{2} \mathrm{O}_{3}$ layer was removed from the surface during the sealing progress, because of the poor adhesion between $\mathrm{Al}_{2} \mathrm{O}_{3}$ and the matrix. This result was consistent with the XRD result, which showed the obvious matrix peaks in the curve.

$\mathrm{Al}$ concentration affected the oxidation progress of the $\mathrm{Fe}-15 \mathrm{Cu}$ alloys obviously, lower concentration such as $\mathrm{Fe}-15 \mathrm{Cu}-5 \mathrm{Al}$ alloy was oxidized heavily, and the oxides were complex, there was no continuous $\mathrm{Al}_{2} \mathrm{O}_{3}$ layer which acted as the protective factor formed on the surface of the alloy. When the concentration of $\mathrm{Al}$ was heightened to 15 at.\%, the oxidation resistance of the alloy oxidized at $800{ }^{\circ} \mathrm{C}$ was reinforced clearly. Few matrix elements were depleted during the oxidation progress, because of the high concentration of the $\mathrm{Al}$ which had more active property and was oxidized at first. On the other side, the protective $\mathrm{Al}_{2} \mathrm{O}_{3}$ layer formed on the surface of the Fe-15Cu-15Al alloy had poor adhesion with the matrix, which would affect the practical application of the alloy, so research on the fine adhesion of the $\mathrm{Al}_{2} \mathrm{O}_{3}$ film would be developed in the next work.

\section{Conclusion}

(1) The oxidation process of $\mathrm{Fe}-15 \mathrm{Cu}$ alloys followed the parabolic law, and the lower $\mathrm{Al}$ concentration caused more serious oxidation. 
(2) Fe-15Cu-15Al alloy had favorable high temperature oxidation resistance, with the parabolic rate constant of $2.31 \times 10^{-11}$ ( 0 to $300 \mathrm{~min}$ ) and $2.07 \times 10^{-12} \mathrm{~g}^{2} \mathrm{~cm}^{-2} \mathrm{~s}^{-1}$ (300-1440 min), respectively.

(3) The adhesion of the $\mathrm{Al}_{2} \mathrm{O}_{3}$ film obtained on the surface of $\mathrm{Fe}-15 \mathrm{Cu}-15 \mathrm{Al}$ alloy was bad, so the cyclic oxidation resistance of the alloy was not good.

\section{References}

[1] Kurt P Rohrach. Development and selection of high temperature alloys[J]. Aerospace materials and technology, 2005, (01): 61 62

[2] Naoya Masahashi, Go Kimura, Masaoki Oku, et al. Corrosion behavior of iron-aluminum alloys and its composite steel in sulfuric acid[J]. Corrosion Seienee, 2006, Vol. 48(4):829 839

[3] Katarzyna Pietrzak, Dariusz Kalinskix, Marcin Chmielewski. Interlayer of A12O3-Cr functionally graded material for reduction of thermal stresses in aluminum-heat resisting steel joints[J]. Journal of the European Ceramic Soceiety, 2007, Vol. 27(2 3): 128

[4] N. Masahashi, G. Kimura, M. Oku, K. Komatsu, S. Watanabe, and S. Hanada, Corrosion Behavior of Iron-Aluminum Alloys and Its Composite Steel in Sulfuric Acid, Corros. Sci., 2006, 48, p 829-839.

[5] F. Lang, Z. Yu, S. Gedeyanishvili, S.C. Deevi, S. Hayashi, and T. Narita, Sulfidation Behavior of Fe-40Al Sheet in $\mathrm{H}_{2}-\mathrm{H}_{2} \mathrm{~S}$ Mixtures at High Temperatures, Intermetallics, 2004, 12, p 469-475.

[6] Y.S. Li and M. Spiegel, Internal Oxidation of Fe-Al Alloys in a KCl-Air Atmosphere at $650^{\circ} \mathrm{C}$, Oxid. Met., 2004, 61, p 303-322. 